\title{
Nonfat Set Yogurt: Effect of Okra Gum and Various Starches on the Rheological, Sensory, and Storage Qualities and Wheying-Off
}

\author{
Ali Saleh, A. A. Mohamed (D, M. S. Alamri, S. Hussain, A. A. Qasem, M. A. Ibraheem, \\ and Syed Ali Shahzad \\ Department of Food Science and Nutrition, King Saud University, Riyadh, Saudi Arabia \\ Correspondence should be addressed to A. A. Mohamed; abdmohamed@ksu.edu.sa
}

Received 18 February 2020; Accepted 23 May 2020; Published 11 June 2020

Academic Editor: Ioannis G. Roussis

Copyright (c) 2020 Ali Saleh et al. This is an open access article distributed under the Creative Commons Attribution License, which permits unrestricted use, distribution, and reproduction in any medium, provided the original work is properly cited.

\begin{abstract}
This work was intended to determine the effect of okra gum in combination with various starches on the flow and sensory properties of nonfat set yogurt. The selected starches include potato (PS), sweet potato (SPS), corn (CO), chickpea (CP), and Turkish beans (TB). The control is the yogurt prepared with okra gum only. Samples were analyzed under optimum conditions for their shear viscosity, viscoelasticity, texture, wheying-off, and sensory evaluation. Tests were performed at the beginning of the cold storage and after 7 or 15 days. By adding 1.0\% starch, significant $(p<0.05)$ reduction in wheying-off and firmer yogurt was obtained. Variations in the properties of yogurt were obvious and can be attributed to starch origin and amylose content. Therefore, the qualities of yogurts with tuber starches (PS and SPS) were different compared to corn or legume starches (CP and TB). The effect of the starches on yogurt properties changed over storage time, where some starches performed better only at the beginning of the storage period, and steady $\mathrm{pH}$ was maintained throughout the storage time. Wheying-off was significantly reduced irrespective of the origin of the starch. Sensory evaluation showed preference for yogurts prepared with starch compared to the control, regardless of starch type. Nonetheless, CP was preferred over other starches with respect to wheying-off, power law parameters, and overall acceptability.
\end{abstract}

\section{Introduction}

Yogurt and other fermented milk products are widely consumed, but yogurt is considered the most popular because of its health benefits [1]. Bacteria such as Lactobacillus bulgaricus and Streptococcus thermophilus are used for yogurt making [2]. Besides the high level of milk solids, yogurt contains nutrients developed during the fermentation process. Optimal consistency and stability during manufacturing, transportation, and storage is one of the challenges of the industry. The main elements that affect the consistency of yogurt are variation in the processing variables, total solids content, and characteristics of the starter culture [3]. Full-fat products' consumption has declined by virtue of consumer awareness of the association of some fats with various diseases caused by ingesting excess fats; therefore, some consumers have changed their eating habits and moved to low or nonfat dairy products [4]. According to the Federal code of the FDA, yogurt with no less than $0.5 \%$ is considered low fat; nonfat should contain no more than $0.5 \%$, whereas full fat is at least $3.25 \%$ fat $[5,6]$. Milk fat is the main factor that determines the texture, flavor, and color of the final products of yogurt [7]. Therefore, low fat yogurt is characterized with weak body, poor texture, and increased whey separation unless various stabilizers are used because the removal of fat leads to low solid content [8].

Hydrocolloids are biopolymers used in the food industry as gelling agents, thickeners, and water controllers and to some degree emulsifiers $[9,10]$. Soluble fiber-rich hydrocolloids are known to lower cholesterol and blood pressure. In addition, they function as flavor encapsulater and aroma regulator [11]. Mucilage is a slimy mass of polysaccharides complex of sugars and uronic acid units typically heterogeneous in composition. Mucilage is primarily extracted from seeds or other plant parts, marine algae, or from particular types of microorganisms [12]. Starch is used for its 
textural properties in many food products and has many industrial applications such as thickening agent, colloidal stabilizer, gelling, filler agent, and water retention. Because of its limited response to high temperatures, $\mathrm{pH}$ and shear native starch has limited applications. Therefore, starches are modified genetically, physically, and chemically to expand its utilization [13]. In addition, the growing demand for starches for industrial applications has created interest in new sources. These modifications can change properties, such as gelatinization, pasting, gel stability, solubility, and swelling power of starch. There are, however, limitations in using physical or chemical treatments because they are costly and have potential to cause environmental pollution. In the food industry, starch can be used to control product uniformity, stability, and texture of soups and sauces or to retard gel breakdown during processing and storage [14].

Abelmoschus esculentus (L.) commonly known as okra is rich in water extractable polysaccharides that can have high viscosity at very low concentrations [15]. Okra polysaccharide extract is characterized as rich in galactose, rhamnose, and galacturonic acid [16]. By virtue of their viscous properties, okra gums are used as fat replacers in chocolate products [17], egg-white substitutes [18], and in frozen dairy products [19]. Starch-gum blends exhibit increased psuedoplasticity compared to starch only; in addition, the texture of starch gel after overnight storage was much harder in the presence of gums indicating physical interaction between starch and gum [20-22]. The motivation of this study was to determine the effect of okra gums in combination with corn, sweet potato, potato, Turkish beans, and chickpea starches on the rheological, textural, and sensory properties of nonfat set yogurt during processing and through storage.

\section{Materials and Methods}

2.1. Materials. Nonfat milk powder (34.5\% protein, $3.5 \%$ moisture, $7.2 \%$ ash, and 55\% lactose) was purchased from a local store (Nestle, NIDO, Switzerland). Fresh potato, sweet potato, and okra pods were obtained from the local produce market (Riyadh, Saudi Arabia). Chickpea and Turkish beans were purchased from local market. Corn starch was donated by ARASCO (Riyadh, Saudi Arabia). The starches used here are different with respect to their botanic source, granule structure, and amylose to amylopectin ratio, which will reflect on the gelatinization temperature and the past properties.

2.2. Okra Gum Extraction. Cut seedless okra ( $100 \mathrm{~g})$ were added to $500 \mathrm{ml} 0.05 \mathrm{M} \mathrm{NaOH}$ and blended for 5 minutes at medium speed in heavy duty blender (B. Braun Melsungen, AG, Hessen, Germany). The slurry was centrifuged at $2 \times 1000 \mathrm{~g}$, and the supernatant was collected. The process was repeated twice on the precipitate. The $\mathrm{pH}$ of the combined supernatants was adjusted to 7.0. The neutralized supernatant was freeze-dried and stored at $4^{\circ} \mathrm{C}$ for further use [23].

\subsection{Starch Extraction}

2.3.1. Potato and Sweet Potato Starches Isolation. The potato or sweet potato starch was isolated according to Sit et al. [24]. The tuber was washed, peeled, diced, and blended in distilled water $(50: 50 \mathrm{v} / \mathrm{v})$ for 3 min using kitchen aid blender (B. Braun Melsungen, AG, Hessen, Germany). Slurry was filtered through a muslin cloth, and the overs were reblended and filtered in the same way. The slurry was sieved through a 200-mesh sieve; the starch was allowed to settle for $1.0 \mathrm{~h}$ at room temperature, and the supernatant was decanted. The settled starch was resuspended in distilled water and centrifuged at $2000 \mathrm{~g}$ for 15 minutes. The top dark layer was removed, and the white material at the bottom of the bottle was resuspended in distilled water and centrifuged. The isolated starch was air-dried, ground, and stored at $4^{\circ} \mathrm{C}$ for further use.

\subsubsection{Chickpea and Turkish Bean Starches Isolation.} Whole meal of chickpea or Turkish beans was prepared by crushing the dry beans in the blender at low speed for $3 \mathrm{~min}$. The whole meal was suspended in distilled water (50/50; w/ $\mathrm{w}$ ) and blended in heavy duty blender for $5 \mathrm{~min}$ (B. Braun Melsungen, AG, Hessen, Germany). The slurry was filtered through a 200-mesh sieve, and the filtrate was centrifuged at $2 \times 1000 \mathrm{~g}$ for $15 \mathrm{~min}$ [25]. The top layer on the precipitate was removed, and the white material at the bottom (the pellet) was resuspended in distilled water and centrifuged as before. This procedure was repeated several times. The starch was air-dried, ground in a coffee grinder, and stored at $4^{\circ} \mathrm{C}$.

2.4. Amylose Content. Amylose content of the isolated starches was determined according to the method in [26]. The method is based on weighing $0.1 \mathrm{~g}$ of starch dry basis, $1.0 \mathrm{ml}$ ethanol, and $9.0 \mathrm{ml} \mathrm{NaOH}(1.0 \mathrm{M})$. The mixture was placed in a boiling water bath for $10 \mathrm{~min}$ and cooled to room temperature. To $5 \mathrm{ml}$ mixture, $1.0 \mathrm{ml}$ acetic acid $(1.0 \mathrm{~N})$ plus $2 \mathrm{ml}$ iodine solution $(2.0 \mathrm{~g}$ of potassium iodide and $0.2 \mathrm{~g}$ of iodine diluted to $100 \mathrm{~mL}$ with distilled water) was added; the absorbance (A) was read at $620 \mathrm{~nm}$, and then, the percent amylose content was calculated using $3.06 \times \mathrm{A} \times 20$.

2.5. Yogurt Preparation. Nonfat yogurt was prepared using powdered skimmed milk, gum, and starch. Portion of the powdered milk was replaced with $10.0 \mathrm{~g}$ of starch and $1.0 \mathrm{~g}$ of gum (okra or cress seed) to maintain a final weight of $140.0 \mathrm{~g}$ in 1.0 lit. The use of starch concentration was decided after a trial of different concentrations, and we found $1 \%$ starch gave good results and does not interfere with texture and taste closer to plain yogurt and customary to the consumer. To enable complete solubility, gums were dissolved in water first, and the dry starch was blended with the milk powder. The gum suspension was added to the dry ingredients $(140 \mathrm{~g})$ and diluted to 1.0 lit with distilled water (14.0\%), and was mixed gently and heated to $60^{\circ} \mathrm{C}$ for $30 \mathrm{~min}$ and cooled to $42^{\circ} \mathrm{C}$; $3 \%$ of yogurt starter was added (based on dry ingredients). The bacterial content of the starter included 
Streptococcus thermophilus and Lactobacillus bulgaricus. The one-liter mixture $(14 \mathrm{~g} / 100 \mathrm{ml})$ was divided into plastic cups $\left(50 \mathrm{ml}\right.$ each) and incubated at $42^{\circ} \mathrm{C}$ till the coagulation occurred or the $\mathrm{pH}$ reached 4.6 [27]. The incubation temperature was decided after a trial at 36,42 , and $45^{\circ} \mathrm{C}$, and by monitoring the texture and the $\mathrm{pH}, 42^{\circ} \mathrm{C}$ was found to be the best incubation temperature because the texture and the $\mathrm{pH}$ of the other temperatures were not satisfactory. After processing, yogurt samples (three replicates) were stored at $5 \pm 0.2^{\circ} \mathrm{C}$ and analyzed after 0,7 , and 15 days of storage. The $\mathrm{pH}$ of yogurt samples was determined at $25^{\circ} \mathrm{C}$.

\subsection{Determination of Yogurt Composition}

2.6.1. Total Solids Content. The yogurt total solids content was determined according to AOAC [28]. Sample (10 g) was dried using forced air oven at $105 \pm 5^{\circ} \mathrm{C}$ for 1.0 hour. After drying, the remaining weight was expressed as percent total solids.

2.6.2. Total Ash Content. The ash content was determined using the AOAC [28], where $5 \mathrm{~g}$ of yogurt was heated at $550^{\circ} \mathrm{C}$ for 5 hours, and the residue was expressed as $\%$ ash content.

2.6.3. Crude Protein. The crude protein content was determined according to the Kjeldahl method as described by AOAC [28]. Yogurt sample ( $2 \mathrm{~g}$ ) was digested in concentrated sulfuric acid, and the total titrated organic nitrogen content was multiplied by 6.38 .

2.6.4. Crude Fat. Crude fat content was determined using the Gerber method, and the percent crude fat was calculated directly by reading the calibrated butyrometer [29].

2.6.5. Total Carbohydrates. The total carbohydrate content was determined by the difference method as expressed below:

$$
\begin{aligned}
\text { carbohydrates }(\%)= & {[100-(\text { protein } \%+\text { fat } \%+\text { moisture } \%} \\
& + \text { ash } \%)] .
\end{aligned}
$$

2.7. Apparent Viscosity. Yogurt viscosity measurements were determined at room temperature $\left(25^{\circ} \mathrm{C}\right)$ using Brookfield viscometer (Brookfield Engineering Inc, Model RV-DV II Pro + spindle number 63). The disc spindle was selected due to the nature of the yogurt and because it allows readings within the sensitivity range of the apparatus. Based on the manufacturer (Brookfield) recommendation, samples should be at $25^{\circ} \mathrm{C}$ for about $10 \mathrm{~min}$ before measurements. To avoid immediate time dependence phenomenon and reaching thermal equilibrium, the first measurements were taken $2.0 \mathrm{~min}$ after the spindle was immersed in the sample. Duplicated data were collected every $40.0 \mathrm{sec}$. The data were transformed into shear rate and shear stress format and fitted to the power law model:

$$
\sigma=k \gamma^{n}
$$

where $\sigma$ is the shear stress (Pas), $\gamma$ is the shear rate $\left(\mathrm{s}^{-1}\right), n$ is the flow behavior index, and $k$ is the consistency index (Pas). The $n$ values were obtained from plotting the log shear stress versus log of shear rate; the slope of the line is equal to the flow index $(n)$.

2.8. Dynamic Rheology and Steady Flow Behavior. The viscoelastic properties of nonfat yogurt were determined using Discovery Hybrid Rheometer (HR-1) equipped with parallel plates system ( $40 \mathrm{~mm}$ in diameter, $50 \mu \mathrm{m}$ gaps, and calibrated at $25^{\circ} \mathrm{C}$ for 1 minute (TA Instruments, New Caste, $\mathrm{PA})$ ). Frequency sweep range was set from 0.1 to $100 \mathrm{rad} / \mathrm{s}$ and $0.5 \%$ constant strain. The data collected represent storage moduli $\left(G^{\prime}\right)$, loss moduli $\left(G^{\prime \prime}\right)$, and viscosity. Strainsweep experiment was performed to ascertain that all measurements were done within the linear viscoelastic range (LVR) of the experiment which signifies that the measured parameters are independent of shear strains. The LVR was determined by increasing the strain sweep from 0.1 to $50.0 \mathrm{Pas}$ at a constant frequency of $0.1 \mathrm{~Hz}(0.628 \mathrm{rad} / \mathrm{s})$. Therefore, the experimental parameters were set at frequency sweep between 0.1 and $10(\mathrm{rad} / \mathrm{s})$ with a constant strain of 1.0 Pas. The parameters of the tested materials in this study were within the LVR and below $1 \%$ strain. Measurement was repeated at least twice with fresh samples, and the relative errors were about $\pm 10 \%$. The data were processed using Rheology Advantage Data Analysis software (Version 5.7.0) provided by TA instrument. The frequency range used here is usually used for frequency sweep to ascertain that $\mathrm{G}^{\prime}, \mathrm{G}^{\prime \prime}$, and $\eta^{*}$ were within the linear region. The viscosity profile was used to provide information about the possibility of sample slippage during the rheological testing. For that reason, the viscosity as a function of shear rate profiles of duplicate runs was plotted in the same graph to establish the repeatability and slippage behavior of the material. No slippage was observed.

2.9. Yogurt Texture Profile Analysis (TPA). Yogurt samples were subjected to compression test using texture analyzer (TA-XT2 Texture Analyzer, Texture Technologies Crop, Scarsdale, NY). The instrument is equipped with a plastic cylinder moving at a speed of $70 \mathrm{~mm} / \mathrm{min}$ in both upward and downward directions (45 Perspex Cone, 432-081). Samples were placed on a leveled plane, and the plastic cylinder was inserted $20 \mathrm{~mm}$ into the surface of the sample. Yogurt firmness was calculated according to the method of Steffe [30]. Gel hardness (firmness) is the measure of the force needed to deform the gel during compression and is related to its structure and strength. The cohesiveness is defined as the strength of hydrogen bonding of the gel and the degree to which food gels can be deformed before it breaks. Adhesiveness is defined as the work required to overcome the attractive forces between the surface of a food 
and the surface of other materials with which the food comes into contact. The springiness is a textural parameter, which is related to elasticity of the sample.

2.10. Whey Separation (Wheying-Off). Yogurt wheying-off is the separating of whey on the surface and expressed as g/ $100 \mathrm{~g}$ yogurt. Spontaneous wheying-off is the whey separation from undisturbed set yogurt and is measured by the siphon drainage method [31]. A sample of set yogurt was removed from the cold room $\left(4^{\circ} \mathrm{C}\right)$, weighed, and placed at approximately $45^{\circ}$ angle to allow whey collection on the side of the cup. Using a syringe, the separated whey was collected every $10 \mathrm{sec}$, and the cup was weighed again. The syneresis (wheying-off) was expressed as the percent weight loss over the initial weight of the yogurt.

2.11. Sensory Evaluation. The sensory evaluation was done by a group of 10 trained sensory judges which included the following sensory characteristics: appearance, color, texture, aroma, taste, aftertaste, and overall acceptability. The scale was set from 1 to 9 points hedonic scale, where 1 is dislike extremely, 5 is for neither like or dislike, and 9 is for extremely like.

2.12. Statistical Analysis. All measurements were done in triplicate, and analysis of variance (ANOVA) was applied using factorial design. Statistical analysis was performed using SPSS. A factorial design with 2 gums, 5 starches, 3 storage times, and 3 replicates $(1 \times 5 \times 3 \times 3)$ Duncan's multiple range tests at $p \leq 0.05$ was used to compare means using PASW ${ }^{\circledR}$ Statistics 18 software (SPSS Inc., Hong Kong, China P.R.).

\section{Results and Discussion}

3.1. Shear Viscosity. The proximate composition of the starch-enriched yogurt and the control showed no significant difference regarding the total solids and ash, but the control exhibited lower carbohydrates and higher protein content. The amylose content for potato (PS), sweet potato (SPS), corn (CO), chickpea (CP), and Turkish bean (TB) starches was $21.8 \%, 22.9 \%, 20.4 \%, 32.2 \%$, and $17.5 \%$, respectively. The effect of the starches on the shear rate and shear stress of the yogurt is shown in Figure 1. In reference to the classification of flow behavior of fluid foods, it shows that all the curves in Figure 1 exhibited non-Newtonian shearthinning behavior, which is a downward curvature on the shear rate axis. Apparent viscosity decreases evidently with increasing shear rate as well as the clear occurrence of yield stress, which indicates an interactive structure [32]. In Figure 1(a), at the beginning of cold storage, samples containing sweet potato and potato starch followed by the control (the control is the sample with okra only) exhibited the highest yield stress, whereas TB starch was the lowest indicating firmer gel in the presence of SPS, PS starch/okra gum, as well as okra only. The softer gel was observed for the
TB starch. Physical gap existing between the profiles of CO, $\mathrm{CP}$, and TB starches was apparent in Figure 1(a), but the control and SPS were almost superimposed on each other. The yield stress of the yogurt samples at the beginning of the storage period can be ranked as $\mathrm{SPS}>\mathrm{PS}>\mathrm{CO}>\mathrm{CP}>$ control $>\mathrm{TB}$. At low shear rate, PS exhibited the highest shear stress until about $60(1 / \mathrm{s})$ but reached plateau after that to the end of the experiment which indicates firm undisturbed gel. Grindrod and Nickerson [33] reported strong interaction between different gums and $k$-casein, which could be the reason why yogurt with okra gum exhibited the highest gel firmness and in combination with sweet potato starch. Therefore, we can infer from Figure 1 that some of the starches used here interfered with okra gum functionality and resulted in softer gel.

After 7 storage days with respect to the yield stress, CP ranked first followed by SPS starch, whereas the effect of the remaining starches was similar except TB. It is clear how storage time can change the effect of the starch on the yield stress because chickpea starch ranked first after 7 days of storage and it was number 4 at the beginning of the storage. This can be attributed to the individual starch granules structure and amylose content. This is evident from the low amylose content of Turkish beans starch and the high amylose content of chickpea starch because high amylose is expected to produce a firmer gel with high yield stress. The samples can be ranked as $\mathrm{CP}>\mathrm{SPS}>\mathrm{CONTROL}>\mathrm{PS}>\mathrm{CO}>\mathrm{TB}$.

One thing for sure is, at longer storage time, SPS became less effective, while the control improved; the $\mathrm{CP}$ had the most enhanced effect on the yield stress. The TB effect was independent of storage time because it remained last through the storage period. After 15 days, the rank was $\mathrm{CP}>$ control $>\mathrm{SPS}>\mathrm{PS}>\mathrm{CO}>\mathrm{TB}$. In general, the gap between the samples was higher compared to the other storage days. Therefore, for short storage time, it is recommended to use SPS, and for longer storage period, CP is more effective. In previous work, Saleh et al. [34] reported the effect of starches only on the set yogurt yield stress and found starches with higher amylose content were less effective in producing firmer gel. In this work, CP which is high in amylose content was the most effective especially at longer storage. This indicates synergy between okra gum and the leached amylose during the heating of the bled before fermentation which resulted in firmer gel. In addition, when using starch, only the PS and CO were recommended for longer storage. These starches were the least effective when used in combination with okra gum.

According to equation (2), the rheological behavior of the yogurt containing okra gum combined with different types of starches was described using the power law. The data in Table 1 include the power law parameters $(k$ and $n)$. The data surly fit the power law because the $r^{2}$ was higher than 0.95 . In the plot of shear rate and shear stress, the $Y$-intercept was represented by the $K$ and the slope by the $n$. In Table 1 , the higher slope reveals higher resistance to shear force, i.e., firmer gel. Irrespective of the number of storage days or starch type, all yogurt samples behaved as pseudoplastic since $n<1$, but they were at different levels of pseudoplasticity. Cruz et al. [35] and Yu et al. [36] reported similar 


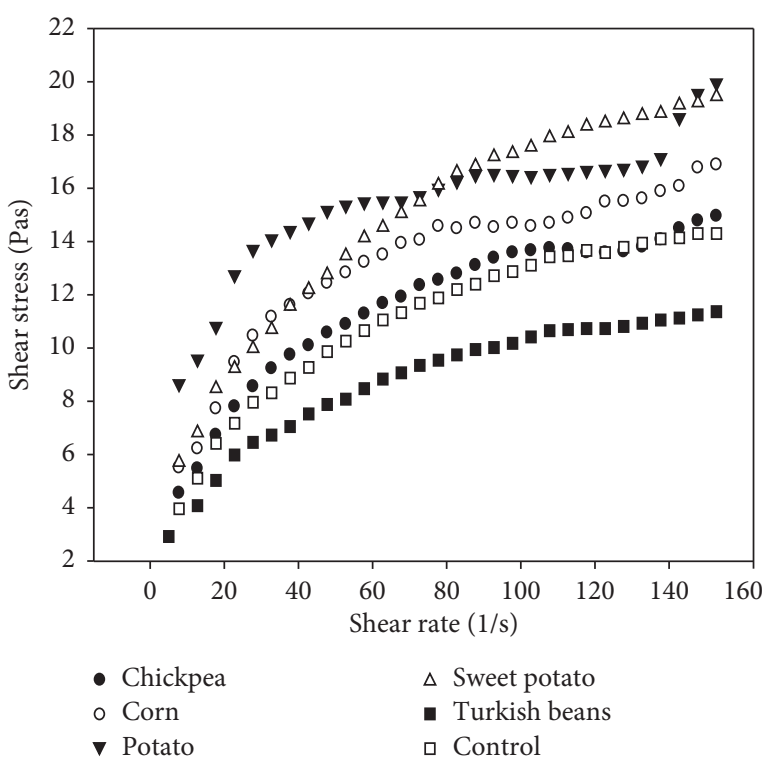

(a)

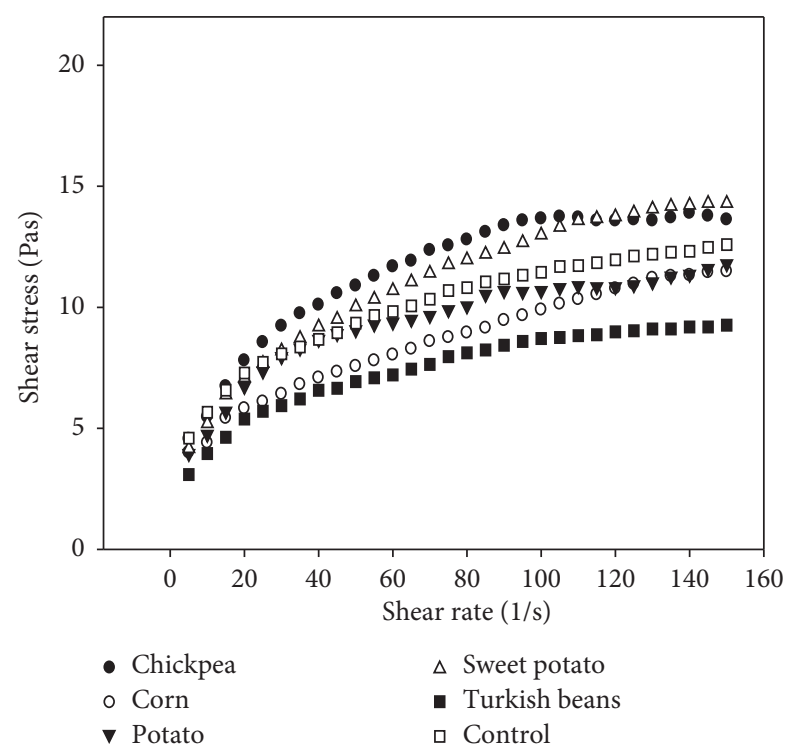

(b)

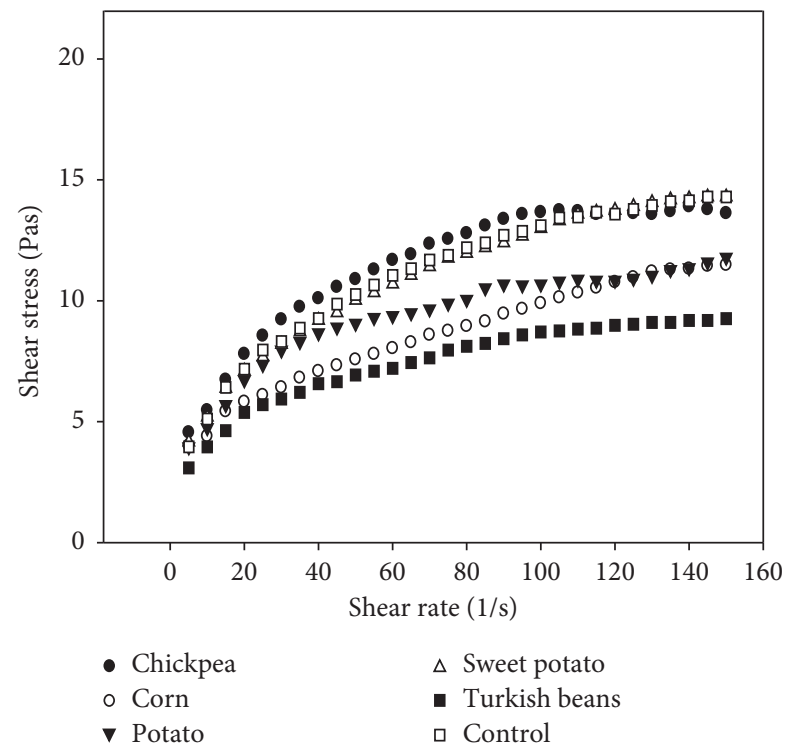

(c)

FIgURE 1: Shear rate/shear stress relationship for yogurt fortified with okra gum and different starches: (a) at the beginning of the cold storage, (b) after 7 days, and (c) after 15 days.

findings. With respect to the $K$ value which represents the viscous properties of the set yogurt, there is a clear difference between the samples due to the type of starch and the storage period. Some samples exhibited increase in the $K$ value after 7 days (SPS, TB, and the control), whereas others showed decrease in $K$ (PS, CO, and $\mathrm{CP}$ ), but after 15 days, some samples maintained the same $K$ value (PS and $\mathrm{CP}$ ) and others had less $K$ (SPS, CO, and TB). This difference can be attributed to the ranking of these samples pertaining to amylose content. The higher viscous property does not necessarily represent firmer gel. At short storage period, CP had the most viscous texture, whereas after 7 days, SPS was the highest and PS was the most viscous after 15 days. Based on the data in Table 1, set yogurt containing PS had unchanged viscosity throughout the storage period; therefore, it can be the best choice for high viscosity set yogurt. This was true when only starch was used as reported by Saleh et al. [34]. This indicates no significant interaction between PS and $K$-casein in the presence of okra gum.

The variation in set yogurt psuedoplasticity as a function of storage time is obvious in Table 1. This suggests structural changes in starch molecules (mostly amylose) which facilitated for interactions with casein network in some cases. PS and SPS maintained the same psuedoplasticity regardless of time, where $\mathrm{CO}, \mathrm{CP}$, and TB exhibited drop in the $n$ value (more pseudoplastic) as a function of storage time, whereas 
TABLE 1: The $k$ and $n$ of yogurt prepared with okra gum and different starches.

\begin{tabular}{lccc}
\hline Treatment & \multicolumn{3}{c}{$K$} \\
\hline Number of days & 0 & 7 & 15 \\
Control & $0.38 \pm 0.01$ & $0.41 \pm 0.01$ & $0.47 \pm 0.06$ \\
Ok & $0.38 \pm 0.05$ & $0.31 \pm 0.01$ & $0.33 \pm 0.01$ \\
PS & $0.46 \pm 0.03$ & $0.45 \pm 0.01$ & $0.45 \pm 0.03$ \\
SPS & $0.47 \pm 0.02$ & $0.55 \pm 0.04$ & $0.36 \pm 0.04$ \\
CO & $0.55 \pm 0.05$ & $0.53 \pm 0.09$ & $0.33 \pm 0.01$ \\
CP & $0.84 \pm 0.03$ & $0.43 \pm 0.06$ & $0.42 \pm 0.01$ \\
TB & $0.25 \pm 0.08$ & $0.36 \pm 0.03$ & $0.29 \pm 0.08$ \\
& & $N$ & \\
\hline & 0 & 7 & 15 \\
Control & $0.38 \pm 0.011$ & $0.31 \pm 0.01$ & $0.29 \pm 0.04$ \\
Ok & $0.38 \pm 0.021$ & $0.23 \pm 0.01$ & $0.32 \pm 0.02$ \\
PS & $0.34 \pm 0.041$ & $0.35 \pm 0.05$ & $0.34 \pm 0.02$ \\
SPS & $0.38 \pm 0.021$ & $0.38 \pm 0.01$ & $0.37 \pm 0.01$ \\
CO & $0.32 \pm 0.022$ & $0.32 \pm 0.01$ & $0.33 \pm 0.03$ \\
CP & $0.19 \pm 0.006$ & $0.31 \pm 0.04$ & $0.11 \pm 0.01$ \\
TB & $0.38 \pm 0.033$ & $0.38 \pm 0.01$ & $0.32 \pm 0.02$ \\
\hline
\end{tabular}

$n=$ flow behavior index (dimensionless); $k=$ consistency index $(\mathrm{Pa})$; $\mathrm{C}=$ control; $\mathrm{OK}=$ okra gum; $\mathrm{PS}=$ potato starch; $\mathrm{SPS}=$ sweet potato starch; $\mathrm{CO}=$ corn starch; $\mathrm{CP}=$ chickpea starch; $\mathrm{TB}=$ Turkish bean starch; 2 for 0 days ranged from 0.97 to 0.99 , for 7 days from 0.98 to 0.99 , and for 15 days from 0.98 to 0.99 .

the control (with okra gum only) behavior was time dependent because the sample became more pseudoplastic over time.

Unlike the control, TB and the SPS samples, and by virtue of the lower $n$ values, CP was the most pseudoplastic, but the yogurt sample containing SPS was the least pseudoplastic up to 15 days of storage period. Conversely, chickpea with the highest amylose content remained as the most pseudoplastic (low $n$ ) throughout the storage time (Table 1). Compared to the control, all starch containing yogurt samples exhibited higher $k$ values (except TB) which indicated a higher viscous and thicker structure (Table 1). The $n$ values at zero days were higher for all starches regardless of amylose content (except for SPS and TB) compared to the control, but for longer storage time, all starches exhibited lower $n$ values (except for CP). Once again, the TB starch yogurt was the thinnest of all samples which could be credited to the low amylose content. The thickest yogurt after 15 days storage was the PS. Other researchers reported that the viscosity of yogurt with added milk solids was rather high [37]. Therefore, we can make thicker yogurt for the same solid content by using the right type of starch which is less expensive as well.

3.2. Viscoelastic Properties. The internal structure of yogurt can be predicted by the dynamic rheological testing. These tests are symbolized by storage modulus ( $\mathrm{G}^{\prime}$, elastic), loss modulus ( $\mathrm{G}^{\prime \prime}$, viscus), the complex viscosity $\eta^{*}$, and $\tan \delta$ (phase angle). All yogurt samples are characterized as weak gel because $G^{\prime}>G^{\prime \prime}$ over the range of 0.1 and 50 Pas. A linear viscoelastic region (LVR) test was established between 0.1 and 10 Pas. For that reason, 1.0 Pas stress was selected for the frequency sweep test. This data agrees with the frequency of other reports of yogurt enriched with milk solids or inulin
[38]. When the $G^{\prime}$ of the LVR is extended as a function of stress sweep, it indicates that $\mathrm{G}^{\prime}$ is independent of the stress and the gel represents solid like material. The extent of LVR of the yogurt samples depends on the starch type, as shown in our previous work [34].

The dependency of $G^{\prime}$ on the frequency is presented in Figure 2. The $\mathrm{G}^{\prime}$ of the control increased after 15 days of cold storage. Yogurt samples with $\mathrm{CP}$ had the highest $\mathrm{G}^{\prime}$ after 7 days and remained unchanged (Figure 2(b)). In the previous publication where starch only was used in yogurt making, the $\mathrm{G}^{\prime}$ of the CP starch was the highest compared to other starches. In the present work where okra gum was added to the same starches, CP starch exhibited the most $G^{\prime}$, but the magnitude was must higher than when only starch was used [34]. TB ranked second with gradual increase in $\mathrm{G}^{\prime}$ as a function of storage time (Figure $2(\mathrm{c})$ ). It is worth mentioning that, for all samples, the final $G^{\prime}$ value is time dependent, especially when the maximum $G^{\prime}$ was reached after 7 days and remained almost the same through the 15 days except for PS where a loss of $G^{\prime}$ was observed after 15 days (Figure 2(d)). Generally, the $\mathrm{G}^{\prime}$ of SPS was slightly higher than PS which can be credited to the higher amylose content of SPS. Overall, the $\mathrm{G}^{\prime}$ of the two tubers (SPS and PS) was comparable, and the legumes (CP and TB) were alike, due the large gap between the start of storage and the 7 days, whereas little gap between 7 and 15 days was noticed (Figures 2(d) and 2(e)). The $\mathrm{G}^{\prime}$ ranking of the yogurt according to type of starch is $\mathrm{CP}>\mathrm{TB}>\mathrm{CO}>\mathrm{SPS}>\mathrm{PS}>$ control. The behavior of corn starch was similar to TB, but on smaller scale because the $\mathrm{G}^{\prime}$ gap between the storage days was similar. Therefore, the gel of the control yogurt (with okra gum only) was low in $\mathrm{G}^{\prime}$, which can be characterized as the weakest of all and CP and TB starch produced yogurt with the firmest gel (structure), whereas yogurt with PS and SPS had the least gel firmness. Therefore, for longer storage time and firmer gels (solid like), it is recommended to use $\mathrm{CP}$ or $\mathrm{TB}$ starches in yogurt preparation. In relation to the complex viscosity $\left(\eta^{*}\right)$ at 0.3 frequency ( $\mathrm{rad} / \mathrm{sec}), \mathrm{CP}$ yogurt exhibited the highest viscosity followed by TB, whereas the least viscous was the control and PS (data are not shown). Samples can be ranked as $\mathrm{CP}>\mathrm{TB}>\mathrm{CO}>\mathrm{SPS}>\mathrm{PS}>$ control. It is obvious how yogurts with legume starches exhibited the highest viscosities, whereas the two tubers had the least, but by far, CP yogurt had 4 times more viscosity compared to tubers (PS and SPS). Although amylose content of TB was the least of all starches, it has the same effect on viscosity as the CP which is the highest in amylose content. This could be due to synergy between okra gum and TB. Therefore, yogurt viscosity could be dependent on synergy with okra gum rather than on the starch amylose content. The viscosity was affected by the storage time because CP showed big gap between the viscosity at the beginning of the storage period and the 7 or 15 days, but no gap was observed between the 7 and 15 days.

3.3. Yogurt Texture Profile Analysis (TPA). The main source of yogurt texture is the physical interaction between casein micelles molecules [39]. Yogurt prepared with okra gum 


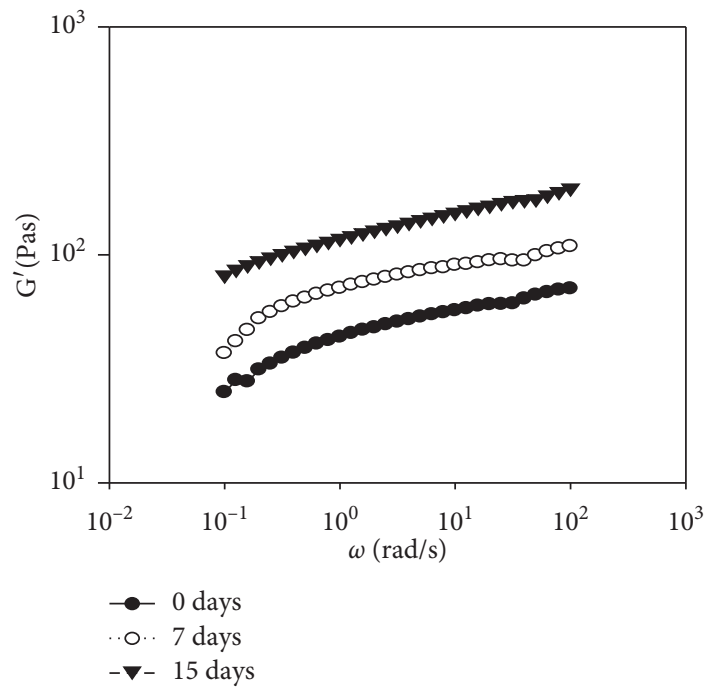

(a)

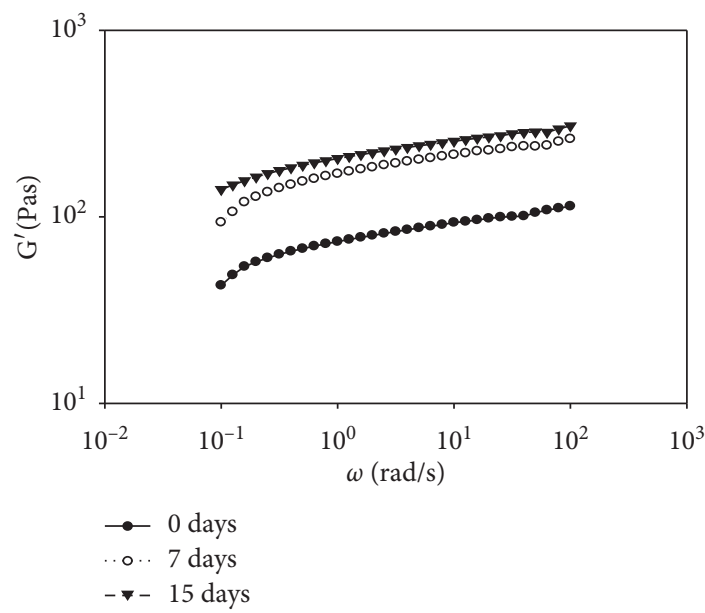

(c)

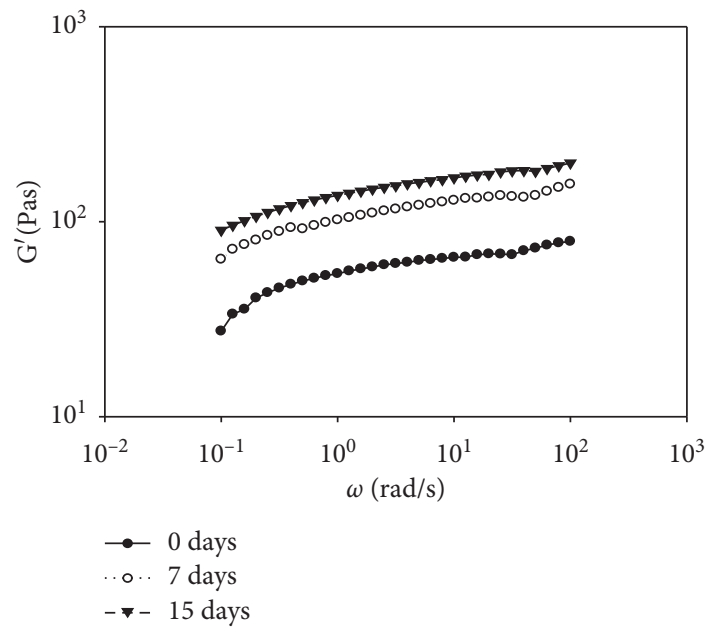

(e)

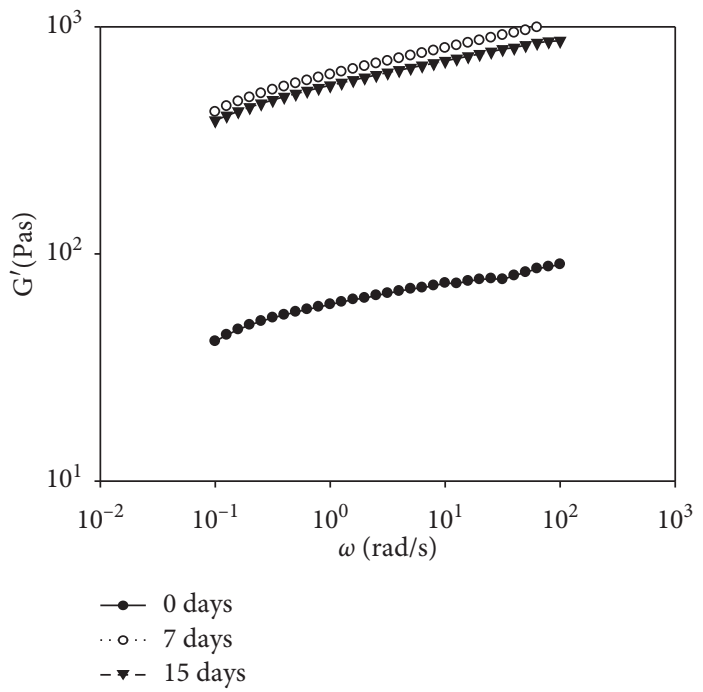

(b)

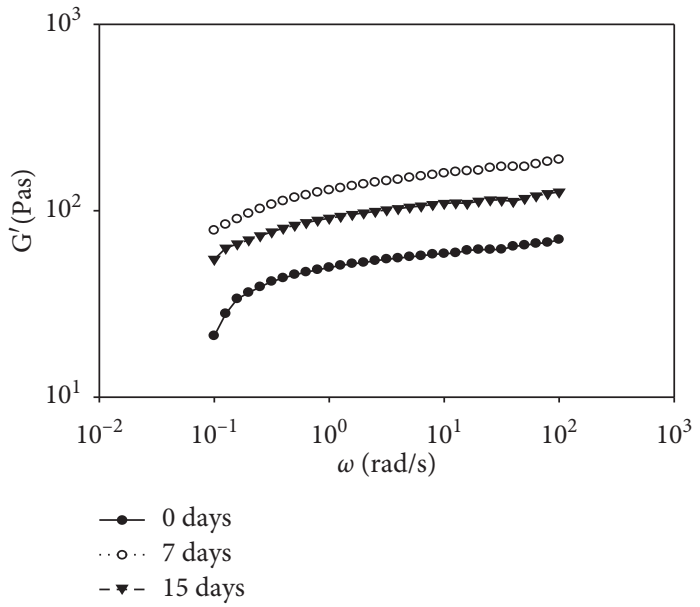

(d)

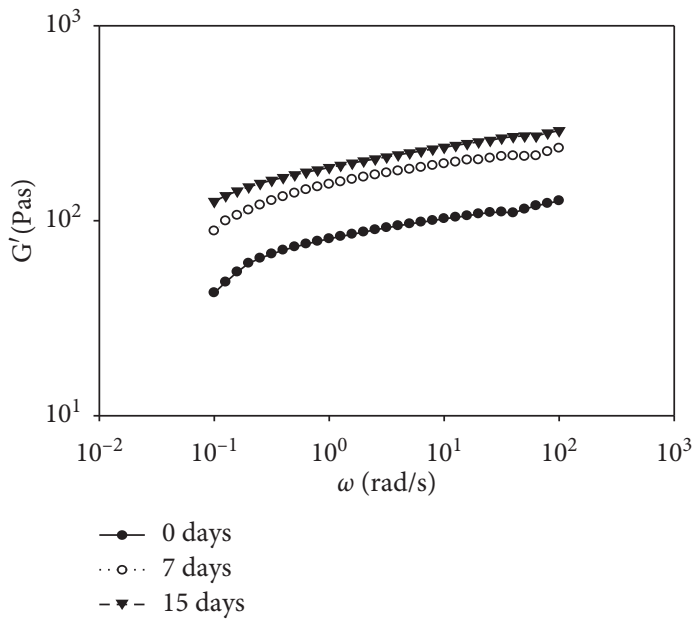

(f)

FIGURE 2: G' of yogurt, okra gum, and different starches blend tested at the beginning of cold storage and after 7 or 15 days: (a) control (only okra); (b)chickpea, (c) corn, (d) potato, (e) sweet potato, and (f) Turkish beans starches. 
TABLE 2: Effect of okra gum and starches addition on texture of yogurt after 0,7 , and 15 days.

\begin{tabular}{|c|c|c|c|c|}
\hline & Hardness (g) & Cohesiveness & Adhesiveness (mJ) & Gumminess (g) \\
\hline \multicolumn{5}{|c|}{ Beginning of cold storage } \\
\hline Control & $30.330 \pm 1.53 \mathrm{a}$ & $0.421 \pm 0.03 a$ & $0.6667 \pm 0.11 \mathrm{a}$ & $12.710 \pm 0.71 \mathrm{a}$ \\
\hline PS & $25.671 \pm 0.58 c$ & $0.240 \pm 0.02 \mathrm{~d}$ & $0.3333 \pm 0.01 c$ & $6.151 \pm 0.41 c$ \\
\hline SPS & $28.000 \pm 1.01 \mathrm{~b}$ & $0.281 \pm 0.10 c$ & $0.6333 \pm 0.02 \mathrm{ab}$ & $7.810 \pm 0.51 b$ \\
\hline $\mathrm{CO}$ & $26.000 \pm 1.01 \mathrm{c}$ & $0.301 \pm 0.10 c$ & $0.6000 \pm 0.01 \mathrm{ab}$ & $7.801 \pm 0.51 b$ \\
\hline $\mathrm{CP}$ & $25.000 \pm 1.02 c$ & $0.291 \pm 0.01 \mathrm{c}$ & $0.7000 \pm 0.13 \mathrm{a}$ & $7.250 \pm 0.47 b$ \\
\hline $\mathrm{TB}$ & $24.670 \pm 1.51 \mathrm{c}$ & $0.430 \pm 0.01 \mathrm{a}$ & $0.4000 \pm 0.10 \mathrm{bc}$ & $10.601 \pm 0.91 b$ \\
\hline \multicolumn{5}{|c|}{7 days storage } \\
\hline Control & $33.010 \pm 1.02 \mathrm{a}$ & $0.491 \pm 0.01 b$ & $0.501 \pm 0.02 \mathrm{a}$ & $16.261 \pm 0.22 \mathrm{a}$ \\
\hline PS & $32.331 \pm 0.58 \mathrm{a}$ & $0.380 \pm 0.01 \mathrm{e}$ & $0.231 \pm 0.06 \mathrm{e}$ & $12.391 \pm 0.22 \mathrm{c}$ \\
\hline SPS & $28.001 \pm 1.02 b$ & $0.340 \pm 0.01 \mathrm{f}$ & $0.471 \pm 0.06 \mathrm{abc}$ & $9.521 \pm 0.31 \mathrm{e}$ \\
\hline $\mathrm{CO}$ & $25.331 \pm 0.58 c$ & $0.410 \pm 0.01 \mathrm{~d}$ & $0.431 \pm 0.06 \mathrm{abc}$ & $10.301 \pm 0.31 \mathrm{de}$ \\
\hline $\mathrm{CP}$ & $24.671 \pm 1.15 c$ & $0.411 \pm 0.01 d$ & $0.371 \pm 0.06 c d$ & $10.111 \pm 0.71 \mathrm{de}$ \\
\hline $\mathrm{TB}$ & $25.331 \pm 0.58 c$ & $0.531 \pm 0.01 \mathrm{a}$ & $0401 \pm 0.02 \mathrm{bcd}$ & $13.341 \pm 0.41 b$ \\
\hline \multicolumn{5}{|c|}{15 days storage } \\
\hline Control & $36.671 \pm 0.58 \mathrm{a}$ & $0.481 \pm 0.01 \mathrm{a}$ & $0.803 \pm 0.13 \mathrm{a}$ & $17.481 \pm 0.60 \mathrm{a}$ \\
\hline PS & $32.001 \pm 1.01 \mathrm{~b}$ & $0.231 \pm 0.01 \mathrm{e}$ & $0.333 \pm 0.06 c$ & $7.474 \pm 0.46 \mathrm{e}$ \\
\hline SPS & $31.330 \pm 0.58 b$ & $0.340 \pm 0.03 c$ & $0.403 \pm 0.10 c$ & $10.651 \pm 0.96 c$ \\
\hline $\mathrm{CO}$ & $28.331 \pm 0.58 c$ & $0.301 \pm 0.01 \mathrm{~d}$ & $0.331 \pm 0.06 c$ & $8.591 \pm 0.17 \mathrm{~d}$ \\
\hline $\mathrm{CP}$ & $25.671 \pm 0.58 \mathrm{~d}$ & $0.351 \pm 0.01 \mathrm{c}$ & $0.333 \pm 0.06 c$ & $8.901 \pm 0.35 d$ \\
\hline $\mathrm{TB}$ & $25.331 \pm 1.53 \mathrm{~d}$ & $0.411 \pm 0.01 \mathrm{~b}$ & $0.372 \pm 0.06 c$ & $10.391 \pm 0.65 c$ \\
\hline
\end{tabular}

Means followed by the same letters within column are not significantly different $(p \leq 0.05)$. Control = yogurt with okra gum; PS = potato starch; SPS $=$ sweet potato starch; $\mathrm{CO}=$ corn starch; $\mathrm{CP}=$ chickpea starch; $\mathrm{TB}=$ Turkish bean starch.

(without starch) exhibited the highest hardness. When starch was introduced in the yogurt-okra blend, the texture was dropped regardless of starch type (Table 2), but it was more prevalent when $\mathrm{CO}, \mathrm{CP}$, and TB starches were added which is true for all storage periods. This indicates physical interaction between starch and okra gum, which in turn reduced okra gum interaction with casein causing drop on the hardness of the yogurt. Conversely, in our previous paper, which was dedicated for the effect of starch only, we reported increase in yogurt hardness regardless of starch type [34]. Storage time was not a major factor on hardness (Table 2). Much drop in hardness was caused by CP and TB after 15 days of cold storage. Once again, the effect of TB and $\mathrm{CP}$ stood out as it did on the $\mathrm{G}^{\prime}$. The range of yogurt hardness was 24-30, 24-32, and 25-36 at the beginning of storage, after 7 days, and after 15 days, respectively, whereas when starch only was used, it was 15-21, 24-31, and 21-32 [34]. It is clear how yogurt was harder in the presence of okra. In addition, yogurt prepared with okra gum only exhibited the hardest gel after 15 days in cold storage, which indicates okra gum, unlike starch, is more effective in longterm storage.

Cohesiveness is the degree of deformation of the material during testing. In the short run, $\mathrm{TB}$ was the most coherent of all despite the fact that it was the least hard gel. Adhesiveness is the attractive force between the food and the teeth which can predict food stickiness. The control was the stickiest yogurt together with all starches except for TB and PS (Table 2). Usually, materials with high adhesion suggest softer texture; this was not true for the control because high adhesion is faced with hard gel (Table 2), but CP exhibited high adhesion and soft gel at the beginning of the cold storage. For longer storage, the low adhesion is met with softer gel. Gumminess is the product of hardness and cohesiveness. The data indicate a typical semisolid food low in hardness and high in cohesiveness. The control was the gummiest throughout the storage time because of the high hardness followed by TB.

3.4. Whey Separation. Wheying-off is undesirable characteristic of set yogurt and defined as the discharge of whey from the casein network. The spontaneous wheying-off of yogurt is the whey separation without any external force and is related to fragile gels. This phenomenon can be due to rearrangements of the gel molecular matrix or by the mechanical damage to the casein network. Yogurt stabilizers, such as starch, pectin, and gelatin, were used by manufacturers to prevent or reduce wheying-off $[11,40,41]$. Common causes of yogurt wheying-off include high incubation time, low $\mathrm{pH}$, uneven ratio of whey protein to casein, low milk solid content, and physical mishandling of the product during storage and distribution. Yogurt treated with $1 \%$ cassava, cross-linked corn starch, and tapioca starch significantly reduced yogurt wheying-off [42]. Regardless of the added amount, potato starch up to $0.75 \%$ was reported to reduce wheying-off [43]. The data reported here showed significant reduction $(p<0.05)$ in wheying-off irrespective of starch type for the same storage period (Table 3). Yogurt without starch or okra gum exhibited the highest wheying-off, but the addition of okra and SPS reduced it by $14 \%$ and $18 \%$, respectively. The presence of okra without starch caused increase in whey separation compared to okra and starch blend, whereas wheying-off was much higher when starch only was used [34]. 
TABLE 3: Effect of okra gum and different starches on whey separation of yogurt at the beginning of storage, after 7 days, and 15 days.

\begin{tabular}{lccr}
\hline & Beginning of storage & 7 days & 15 days \\
\hline Control & $14.31 \pm 0.52 \mathrm{~cd}$ & $22.67 \pm 0.57 \mathrm{bc}$ & $30.01 \pm 1.00 \mathrm{~b}$ \\
PS & $15.01 \pm 0.00 \mathrm{bc}$ & $23.00 \pm 1.00 \mathrm{~b}$ & $29.67 \pm 0.58 \mathrm{~b}$ \\
SPS & $13.67 \pm 0.58 \mathrm{e}$ & $20.00 \pm 1.00 \mathrm{~d}$ & $29.67 \pm 0.57 \mathrm{~b}$ \\
CO & $14.00 \pm 0.50 \mathrm{de}$ & $21.33 \pm 0.58 \mathrm{~cd}$ & $29.67 \pm 0.57 \mathrm{~b}$ \\
CP & $14.67 \pm 0.58 \mathrm{c}$ & $22.00 \pm 1.00 \mathrm{bc}$ & $29.67 \pm 0.58 \mathrm{~b}$ \\
TB & $15.61 \pm 0.580 \mathrm{a}$ & $21.67 \pm 0.57 \mathrm{bc}$ & $30.33 \pm 0.58 \mathrm{~b}$ \\
\hline
\end{tabular}

Means followed by the same letters within column are not significantly different $(p \leq 0.05)$. Control $=$ yogurt with okra gum; PS $=$ potato starch; SPS $=$ sweet potato starch; $\mathrm{CO}=$ corn starch; $\mathrm{CP}=$ chickpea starch; $\mathrm{TB}=$ Turkish bean starch.

TABLE 4: Effect of okra gum and starches on sensory attributes of yogurt.

\begin{tabular}{lccccccc}
\hline Treatments & Viscosity & Texture & Creaminess & Flavor & Mouth feel & Color & Overall acceptability \\
\hline Control & $5.41 \pm 1.07 \mathrm{~b}$ & $5.200 \pm 0.65 \mathrm{~b}$ & $5.30 \pm 0.67 \mathrm{a}$ & $5.20 \pm 0.61 \mathrm{~b}$ & $5.51 \pm 0.85 \mathrm{c}$ & $5.33 \pm 0.71 \mathrm{c}$ & $5.40 \pm 0.84 \mathrm{~b}$ \\
PS & $6.61 \pm 0.84 \mathrm{a}$ & $6.600 \pm 0.84 \mathrm{a}$ & $6.70 \pm 0.82 \mathrm{a}$ & $6.60 \pm 0.84 \mathrm{a}$ & $7.16 \pm 0.74 \mathrm{a}$ & $6.40 \pm 0.71 \mathrm{~b}$ & $6.60 \pm 0.84 \mathrm{a}$ \\
SPS & $6.51 \pm 1.18 \mathrm{a}$ & $6.400 \pm 1.07 \mathrm{a}$ & $6.50 \pm 1.18 \mathrm{a}$ & $6.31 \pm 1.06 \mathrm{a}$ & $6.92 \pm 1.32 \mathrm{ab}$ & $5.80 \pm 1.03 \mathrm{cb}$ & $6.30 \pm 1.06 \mathrm{a}$ \\
CO & $6.01 \pm 1.11 \mathrm{ab}$ & $6.200 \pm 1.23 \mathrm{a}$ & $6.21 \pm 1.23 \mathrm{ab}$ & $6.31 \pm 1.16 \mathrm{a}$ & $6.81 \pm 1.23 \mathrm{ab}$ & $5.51 \pm 0.84 \mathrm{c}$ & $6.00 \pm 1.05 \mathrm{a}$ \\
CP & $6.80 \pm 1.30 \mathrm{a}$ & $6.500 \pm 1.08 \mathrm{a}$ & $6.41 \pm 0.97 \mathrm{a}$ & $6.51 \pm 1.08 \mathrm{a}$ & $6.91 \pm 1.21 \mathrm{av}$ & $6.10 \pm 0.73 \mathrm{~b}$ & $6.40 \pm 0.97 \mathrm{a}$ \\
TB & $6.60 \pm 1.17 \mathrm{a}$ & $6.400 \pm 1.07 \mathrm{a}$ & $6.51 \pm 0.97 \mathrm{a}$ & $6.51 \pm 0.97 \mathrm{a}$ & $6.81 \pm 0.57 \mathrm{ab}$ & $6.20 \pm 0.92 \mathrm{ab}$ & $6.40 \pm 1.07 \mathrm{a}$ \\
\hline
\end{tabular}

1 represents dislike extremely, 5 for neither dislike or like, and 9 for like extremely; means followed by the same letters within column are not significantly different $(p \leq 0.05)$; control = okra gum; PS = potato starch; SPS = sweet potato starch; $\mathrm{CO}=$ corn starch; $\mathrm{CP}=$ chickpea starch; TB = Turkish bean starch. These parameters represent subjective likeness of the panel and is not absolute value.

Wheying-off increased significantly after 7 or 15 days, but the surge was significantly less than that of the control. Therefore, wheying-off was time dependent rather than starch type (Table 3). Modified starches compared to native starches can be more effective in reducing wheying-off [44].

3.5. Sensory Evaluation. Generally, yogurt texture is the leading physical property that defines its sensory quality and overall consumer acceptability. Moreover, yogurt coherency is as important as flavor, in addition to acceptable texture without syneresis is critical for excellent final product as well. Yogurt texture is generally measured using a spoon or directly on the tongue. Yogurt sample is considered viscous if it remained on the tongue or is swallowed with difficulty, while visually by tilting the spoon and identifying the sample flow. The parameters listed in Table 4 represent subjective likeness of the panel and are not absolute value. The statistical analysis pointed out that there was no significant difference $(p>0.05)$ between the starches with regard to sensory viscosity, texture, creaminess, flavor, and mouth feel, but it was significantly higher than the control (Table 4). Regardless of starch type, the panelist overall acceptability of the yogurt was not significantly different $(p<0.05)$, but the starch-containing yogurt was better accepted compared to the samples with or without okra gum. Potato, chickpea, and Turkish beans starches were better accepted than the other starches.

\section{Conclusion}

It is clear how starches had different effects on the final product of yogurt in the presence of okra gum. With respect to the testing methods, chickpea starch had the most influence on the tested qualities of yogurt. Regarding yogurt texture, storage modulus $\left(G^{\prime}\right)$, complex viscosity, yield stress, and wheying-off, chickpea starch ranked first. The effect of chickpea starch was independent of cold storage time. This can be attributed to the higher amylose content compared to other starches. Therefore, it can be recommended over the other starches. Some of these starches had negative effect on yogurt in the presence of okra gum. This was obvious on the texture drop of yogurt-okra gum blend in the presence of Turkish beans starch.

\section{Data Availability}

Data, raw or processed, are available upon request.

\section{Conflicts of Interest}

The authors declare that they have no conflicts of interest.

\section{Acknowledgments}

The authors extend their appreciation to the Deanship of Scientific Research at King Saud University for funding this work through research group no. RG-1441-405.

\section{References}

[1] M. C. Mckinley, "The nutrition and health benefits of yoghurt," International Journal of Dairy Technology, vol. 58, no. 1, pp. 1-12, 2005.

[2] A. Y. Tamime and R. K. Robinson, Yoghurt: Science and Technology, CRC Press, Baco Raton, FL, USA, 1999.

[3] S. Omer, "Chemical and physical properties of yoghurt from khartoum dairy product company (KDPC)," M.S. thesis, Faculty of Animal Production, University Khartoum, Khartoum, Sudan, 2003. 
[4] C. S. Brennan and C. M. Tudorica, "Carbohydrate-based fat replacers in the modification of the rheological, textural and sensory quality of yoghurt: comparative study of the utilisation of barley beta-glucan, guar gum and inulin," International Journal of Food Science \& Technology, vol. 43, no. 5, pp. 824-833, 2008.

[5] FDA, Low Fat Yogurt, 21 CFR 131.203, Code of Federal Regulations, US Department of Health and Human Services, Washington, DC. USA, 1996.

[6] FDA, Nonfat Yogurt, 21 CFR 131.206, Code of Federal Regulations, US Department of Health and Human Services, Washington, DC, USA, 1996.

[7] Z. U. Haque and T. Ji, "Cheddar whey processing and source: II. Effect on non-fat ice cream and yoghurt1," International Journal of Food Science and Technology, vol. 38, no. 4, pp. 463-473, 2003.

[8] V. V. Mistry and H. N. Hassan, "Manufacture of nonfat yogurt from a high milk protein powder," Journal of Dairy Science, vol. 75, no. 4, pp. 947-957, 1992.

[9] J. A. Lucey, "Formation and physical properties of milk protein gels," Journal of Dairy Science, vol. 85, no. 2, pp. 281-294, 2002.

[10] E. Nikoofar, M. Hojjatoleslami, and M. A. Shariaty, "Surveying the effect of quince seed mucilage as a fat replacer on texture and physicochemical properties of semi fat set yoghurt," International Journal of Farming and Allied Science, vol. 2, no. 20, pp. 861-865, 2013.

[11] Q. Zhao, M. Zhao, B. Yang, and C. Cui, "Effect of xanthan gum on the physical properties and textural characteristics of whipped cream," Food Chemistry, vol. 116, no. 3, pp. 624-628, 2009.

[12] D. Rangari Vinod, Alternative System of Medicines. Pharmacognosy \& Phytochemistry, Vol. 1, Elsevier, Amsterdam, Netherlands, 1st edition, 2002.

[13] R. Williams, O. Glagovskaia, and M. Augustin, "Properties of stirred yogurts with added starch: effects of alterations in fermentation conditions," Australian Journal of Dairy Technology, vol. 58, no. 3, p. 228, 2003.

[14] M. Radi, M. Niakousari, and S. Amiri, "Physicochemical, textural and sensory properties of low-fat yogurt produced by using modified wheat starch as a fat replacer," Journal of Applied Sciences, vol. 9, no. 11, pp. 2194-2197, 2009.

[15] G. Onunkwo, "Physical properties of sodium salicylate tablets formulated with Abelmoschus esculentus gum as binder," Acta Pharmaceutica (Zagreb), vol. 46, no. 2, pp. 101-107, 1996.

[16] N. Sengkhamparn, R. Verhoef, H. A. Schols, T. Sajjaanantakul, and A. G. J. Voragen, "Characterisation of cell wall polysaccharides from okra (Abelmoschus esculentus (L.) Moench)," Carbohydrate Research, vol. 344, no. 14, pp. 1824-1832, 2009.

[17] J. E. Romanchik-Cerpovicz, R. W. Tilmon, and K. A. Baldree, "Moisture retention and consumer acceptability of chocolate bar cookies prepared with okra gum as a fat ingredient substitute," Journal of the American Dietetic Association, vol. 102, no. 9, pp. 1301-1303, 2002.

[18] A. J. Costantino and J. E. Romanchik-Cerpovicz, "Physical and sensory measures indicate moderate fat replacement in frozen dairy dessert is feasible using okra gum as a milk-fat ingredient substitute," Journal of the American Dietetic Association, vol. 104, p. 44, 2004.

[19] J. E. Romanchik-Cerpovicz, A. C. Costantino, and L. H. Gunn, "Sensory evaluation ratings and melting characteristics show that okra gum is an acceptable milk-fat ingredient substitute in chocolate frozen dairy dessert," Journal of the American Dietetic Association, vol. 106, no. 4, pp. 594-597, 2006.

[20] M. S. Alamri, A. A. Mohamed, and S. Hussain, "Effects of alkaline-soluble okra gum on rheological and thermal properties of systems with wheat or corn starch," Food Hydrocolloids, vol. 30, no. 2, pp. 541-551, 2013.

[21] M. S. Alamri, A. Mohamed, S. Hussain, and J. Xu, "Effect of okra extract on properties of wheat, corn and rice starches," Journal of Food, Agriculture \& Environment, vol. 10, no. 1, pp. 217-222, 2012.

[22] S. A. Shahzad, S. Hussain, M. S. Alamri et al., "Use of hydrocolloid gums to modify the pasting, thermal, rheological, and textural properties of sweet potato starch," International Journal of Polymer Science, vol. 2019, Article ID 6308591, 11 pages, 2019.

[23] M. S. Alamri, A. A. Mohamed, and S. Hussain, "Effect of okra gum on the pasting, thermal, and viscous properties of rice and sorghum starches," Carbohydrate Polymers, vol. 89, no. 1, pp. 199-207, 2012.

[24] N. Sit, S. Misra, and S. C. Deka, "Physicochemical, functional, textural and colour characteristics of starches isolated from four taro cultivars of North-East India," Starch-Stärke, vol. 65, no. 11-12, pp. 1011-1021, 2013.

[25] N. Singh, K. Singh Sandhu, and M. Kaur, "Characterization of starches separated from Indian chickpea (Cicer arietinum L.) cultivars," Journal of Food Engineering, vol. 63, no. 4, pp. 441-449, 2004.

[26] V. R. Williams, W.-T. Wu, H. Y. Tsai, and H. G. Bates, "Rice starch, varietal differences in amylose content of rice starch," Journal of Agricultural and Food Chemistry, vol. 6, no. 1, pp. 47-48, 1958.

[27] E. Barrantes, A. Tamime, and A. Sword, "Production of lowcalorie yogurt using skim milk powder and fat-substitute. III: microbiological and organoleptic qualities," Milchwissenschaft, vol. 49, no. 4, pp. 205-208, 1994.

[28] AOAC, Official Methods of Analysis of Association of Official Analytical Chemists, AOAC, Rockville, MD, USA, 18th edition, 2007.

[29] R. Badertscher, T. Berger, and R. Kuhn, "Densitometric determination of the fat content of milk and milk products," International Dairy Journal, vol. 17, no. 1, pp. 20-23, 2007.

[30] J. F. Steffe, Rheological Methods in Food Process Engineering, Freeman Press, New York, NY, USA, 1996.

[31] T. Amatayakul, A. L. Halmos, F. Sherkat, and N. P. Shah, "Physical characteristics of yoghurts made using exopolysaccharide-producing starter cultures and varying casein to whey protein ratios," International Dairy Journal, vol. 16, no. 1, pp. 40-51, 2006.

[32] F. Butler and P. McNulty, "Time dependent rheological characterisation of buttermilk at $5{ }^{\circ} \mathrm{C}$," Journal of Food Engineering, vol. 25, no. 4, pp. 569-580, 1995.

[33] J. Grindrod and T. A. Nickerson, "Effect of various gums on skimmilk and purified milk proteins," Journal of Dairy Science, vol. 51, no. 6, pp. 834-841, 1968.

[34] A. Saleh, A. A. Mohamed, M. S. Alamri, S. Hussain, A. A. Qasem, and M. A. Ibraheem, "Effect of different starches on the rheological, sensory and storage attributes of non-fat set yogurt," Foods, vol. 9, no. 1, p. 61, 2020.

[35] A. G. Cruz, W. F. Castro, J. A. F. Faria et al., "Probiotic yogurts manufactured with increased glucose oxidase levels: postacidification, proteolytic patterns, survival of probiotic microorganisms, production of organic acid and aroma compounds," Journal of Dairy Science, vol. 95, no. 5, pp. 2261-2269, 2012. 
[36] H.-Y. Yu, L. Wang, and K. L. McCarthy, "Characterization of yogurts made with milk solids nonfat by rheological behavior and nuclear magnetic resonance spectroscopy," Journal of Food and Drug Analysis, vol. 24, no. 4, pp. 804-812, 2016.

[37] Ö. Gün and N. D. Işıklı, "Effect of fat and non-fat dry matter of milk, and starter type, on the rheological properties of set during the coagulation process," International Journal of Food Science \& Technology, vol. 42, no. 3, pp. 352-358, 2007.

[38] T. Paseephol, D. M. Small, and F. Sherkat, "Rheology and texture of set yogurt as affected by inulin addition," Journal of Texture Studies, vol. 39, no. 6, pp. 617-634, 2008.

[39] A. Vercet, R. Oria, P. Marquina, S. Crelier, and P. LopezBuesa, "Rheological properties of yoghurt made with milk submitted to manothermosonication," Journal of Agricultural and Food Chemistry, vol. 50, no. 21, pp. 6165-6171, 2002.

[40] M. Isleten and Y. Karagul-Yuceer, "Effects of dried dairy ingredients on physical and sensory properties of nonfat yogurt," Journal of Dairy Science, vol. 89, no. 8, pp. 2865-2872, 2006.

[41] M. Guven, K. Yasar, O. B. Karaca, and A. A. Hayaloglu, "The effect of inulin as a fat replacer on the quality of set-type lowfat yogurt manufacture," International Journal of Dairy Technology, vol. 58, no. 3, pp. 180-184, 2005.

[42] H. MwizerwA, G. Ooko Abong, M. Okoth, M. Ongol, C. Onyango, and P. Thavarajah, "Effect of resistant cassava starch on quality parameters and sensory attributes of yoghurt," Current Research in Nutrition and Food Science Journal, vol. 5, no. 3, pp. 353-367, 2017.

[43] A. Altemimi, "Extraction and optimization of potato starch and its application as a stabilizer in yogurt manufacturing," Foods, vol. 7, no. 2, p. 14, 2018.

[44] M. Singh and J. A. Byars, "Starch-lipid composites in plain set yogurt," International Journal of Food Science \& Technology, vol. 44, no. 1, pp. 106-110, 2009. 